\title{
Arctic Profiles: Second Series
}

In the June 1982 issue of Arctic, Richard Davis introduced "Arctic Profiles." At the time he said the purpose of the series was to cover "a more subjective and human element that has influenced the history of arctic development." He continued, "Should this series prove successful . . ." more could follow.

In fact the series has proved extremely successful. The response received by all associated with the production of Arctic is that the Profiles are a favourite segment. Richard's initiative has surpassed expectations. Unfortunately, however, he feels he has done his part and is moving on to other endeavours. Therefore, on behalf of all Arctic readers, we thank him and his contributors for introducing and maintaining the publication of those wonderful bits of human history in the North.

Because of the success of the Profiles, Arctic has decided to maintain the series and has asked us to see it through a second phase. We agreed but thought it was time to consider new opportunities in the nature of the project.

The North today is a region in which one sees the clash of at least three cultures. It is the home of two of Canada's indigenous peoples, the Dene and the Inuit. Thousands of years ago these people moved in and adapted to one of the most challenging environments in all the world. Their survival under almost inhuman conditions obviously nurtured strong cultural roots.

For a few Canadians the North symbolizes the last frontier, a region for dreamers, a region where individuals seek riches or self-sufficiency, or both. The challenge for these people is to use one's intuition to live as independently as possible.

And finally, for most Canadians the North represents a vast storehouse of resources to be extracted for domestic and foreign consumption. It has supplied or is supplying whales, furs, fish, minerals and oil for a modern urban and industrial society. For these people, the vast region and harsh climate is only a challenge to the efficient movement of resources to a gluttonous market. The consequences of clashes between the groups makes the North one of the most interesting and dynamic regions of Canada.

The second series of Arctic Profiles will be used to illustrate the human elements of this dynamic. These profiles will demonstrate how the clash of cultures appears in the lives of individuals in the North. The second series of profiles will be more contemporary but continue to recognize the contribution of those no longer active or alive. They will be used to recognize the unsung heroes who in many instances in their own quiet way have made a real contribution to the North. For instance, there are individuals whose work at the community level, in business, in government, in teaching or nursing, or in churches and other vocations have added a great deal to the enrichment of life. The dedication and service of these people will be recognized. While the profiles are not definitive statements on the lives of the individuals, they will tell the story of how the lives of these people are an integral part of the change going on in the North.

Secondly, we will focus on specific topics that are of interest and illustrate the problem of change in the North. One might consider, for example, transportation and examine its development from snowshoes to sledges or water transport to aviation. In addition, one might consider items such as clothing, food or habitation, all vital components of the lifestyle of people in the North. In examining these topics, again we will focus on the contributions of particular individuals. Coverage of such topics will also offer an opportunity to explore some of the distinctive technologies that have evolved.

The series will be launched with a profile on a northern artist. Kalvak was born in the Arctic Islands and experienced both traditional and modern lifestyles. Leo Bushman, Associate Professor Emeritus of the Art Department at the University of Calgary and Art Curator and Research Associate of the Arctic Institute of North America, had the opportunity to work with Kalvak on Holman Island. He recalls experiences and offers impressions of her work as an artist. This profile and examples of her work seem a fitting start for a new series recognizing contributions in the North.

Please note also that the series remains open to change. We invite comments or suggestions.

\author{
Mark O. Dickerson \\ Len V. Hills \\ Arctic Profiles Editors
}

